\title{
Resources, Knowledge and Influence: The Organizational Effects of Interorganizational Collaboration *
}

\author{
Cynthia Hardy \\ Department of Management \\ University of Melbourne \\ Parkville, Victoria \\ Australia 3010 \\ Tel: (61-3) 8344-5344 \\ Fax: (61-3) 9349-4292 \\ Email: chardy@unimelb.edu.au \\ Nelson Phillips \\ Faculty of Management \\ McGill University \\ 1001 Sherbrooke St. West \\ Montreal, Quebec H3A 4G1 \\ Tel: (514) 398-3602 \\ Fax: (514) 398-3876 \\ E-mail: phillips@management.mcgill.ca \\ Thomas B. Lawrence \\ Faculty of Business \\ University of Victoria \\ P.O. Box 1700 \\ Victoria, BC \\ Canada V8W 2 Y2 \\ Tel: 250-721-6401 \\ Fax: 815-377-4238 \\ E-mail: tlawrenc@business.uvic.ca
}

\footnotetext{
* The authors wish to acknowledge the financial support of the Social Sciences and Humanities Research Council of Canada, les Fonds pour la Formation des Chercheurs et l'Aide à la Recherche of Quebec and the University of Melbourne in carrying out this research.
} 


\section{Resources, Knowledge and Influence: The Organizational Effects of Inter-organizational Collaboration}

Inter-organizational collaboration has been linked to a range of important outcomes for collaborating organizations. The strategy literature emphasizes the way in which collaboration between organizations results in the sharing of critical resources and facilitates knowledge transfer. The learning literature argues that collaboration not only transfers existing knowledge among organizations, but also facilitates the creation of new knowledge and produce synergistic solutions. Finally, research on networks and interorganizational politics suggests that collaboration can help organizations achieve a more central and influential position in relation to other organizations. While these effects have been identified and discussed at some length, little attention has been paid to the relationship between them and the nature of the collaborations that produce them. In this paper, we present the results of a qualitative study that examines the relationship between the effects of interorganizational collaboration and the nature of the collaborations that produce them. Based on our study of the collaborative activities of a small, nongovernmental organization (NGO) in Palestine over a four-year period, we argue that two dimensions of collaboration - embeddedness and involvement - determine the potential of a collaboration to produce one or more of these effects. 


\section{INTRODUCTION}

In this paper, we present the results of a study of the effects of interorganizational collaboration on the collaborating organizations. We explore three types of effects discussed in the collaboration literature: (a) strategic effects; (b) knowledge creation effects; and (c) political effects. Based on a qualitative study of eight different collaborations initiated by one organization, we present a model of the relationship between the characteristics of collaborative relationships and the different effects that they produce. ${ }^{1}$ This model is based on the findings of a qualitative study of all of the collaborations of one organization that adopted an explicit strategy of collaboration. Mère et Enfant (Palestine) is a small, nongovernmental organization (NGO) that provides nutritional services to women and children in Palestine. It adopted an explicit strategy of collaboration in response to its position as a small, under-resourced player in the region. As a result, it collaborated in different ways with a broad range of organizations and, in so doing, produced different strategic, knowledge creation and political effects.

This paper makes two sets of contributions to our understanding of the effects of interorganizational collaboration. The first set of contributions involves the integrative approach of our study. As Gulati, Nohria and Zaheer (2000a, p. 204) argue: “this considerable and growing research tradition in the strategic management field attests to the importance of interfirm relationships generally within the conversation of strategic management, and highlights the need for coalescing and focusing the research in this area.” What is true for the strategy literature is also true more generally. While different effects of collaboration have been studied in a variety of different literatures, involving research on business, government and nonprofit organizations, and adopting both managerial and critical perspectives, these literatures do not, in most cases, 
refer to each other. Instead, they have developed into separate bodies of work through the accumulation of individual studies that each focus on a particular sub-set of effects. The result is a set of interrelated and overlapping literatures, each focusing on a particular set of effects, but with no systematic attempt to bring them together. There is, therefore, a need for a broader approach to studying collaboration. Our paper, accordingly, adopts a more comprehensive approach than much of the work on collaboration in integrating diverse literatures to identify different kinds of collaborative effects and then empirically and systematically exploring them. In this way, we are able to highlight the relationships that connect them, as well as important tensions that can arise between them.

The second set of contributions stems from our use of an in-depth, qualitative research methodology. Although interorganizational collaborations have been examined widely, few studies provide rigorous, qualitative examinations of the effects of collaborative processes. Instead, the study of networks and alliances has been dominated by studies using quantitative descriptions, large samples and statistical analyses. While such quantitative studies have proved invaluable in furthering our understanding of precise, specific, individual effects of collaboration and their relationship to a host of other factors, they have not helped us develop a more comprehensive understanding of what is involved in collaboration. Our multiple case study design of multiple instances of collaboration by one organization involves a holistic analysis of collaboration and is similar in approach to Jehn's (1997) inductive, qualitative study of conflict in which she provided an integrative model in a mature area of inquiry. In this way, our use of a qualitative methodology helps us to develop theory that integrates some of the more focused, detailed studies of specific facets of collaboration and its effects and to deal with the nuanced, process elements of collaboration that are not accessible through traditional, qualitative methods. 
We present our arguments in four steps. First, we draw on the various collaboration literatures to discuss different effects of interorganizational collaboration. Based on this discussion, we pose our research questions. Second, we describe the research site and the methodology we used to study Mère et Enfant ${ }^{2}$ and the collaborations in which it was involved. Third, we present the results of the analysis of these cases and develop three propositions regarding the relationship between particular characteristics of collaboration and the strategic, knowledge creation and political effects. Finally, we discuss our conclusions.

\section{THE EFFECTS OF COLLABORATION}

In this paper, we focus on the effects of interorganizational collaboration. While a range of different definitions of collaboration exists in the literature, we define collaboration as a cooperative, interorganizational relationship that is negotiated in an ongoing communicative process, and which relies on neither market nor hierarchical mechanisms of control (Heide, 1994; Lawrence, Phillips \& Hardy, 1999; Milne, Iyer \& Gooding-Williams, 1996; Phillips, Lawrence \& Hardy, 2000). This definition of collaboration is inclusive enough to encompass a wide range of collaborative arrangements (e.g., consortium, alliances, joint ventures, roundtables, networks, associations), and yet provides a set of critical characteristics that distinguishes it from other forms of interorganizational activity. Most importantly, it distinguishes collaboration from those interorganizational relationships that are cooperative, but where cooperation is either purchased, as in a firm's supplier relationships, or based on some form of legitimate authority, as in a relationship that might occur between a state regulatory agency and a firm operating within its jurisdiction (Grant \& Baden-Fuller, 1995).

Collaboration has been studied in a wide variety of literatures, each of which have emphasized different effects (Powell, Koput \& Smith-Doerr, 1996). For example, the strategy 
literature (e.g., Afuah, 2000; Dyer \& Singh, 1998; Gulati et al., 2000a; Hamel, 1991; Hamel, Doz \& Prahalad, 1989; Hennart, 1988; Teece, 1986; Williamson, 1991) emphasizes its role in helping organizations acquire resources and skills that cannot be produced internally. A similar approach can be found in domain theory (e.g., Gray, 1989; Trist, 1983), which argues that collaboration helps to pool resources and produce solutions to social problems. Work on learning and innovation (e.g., Anand \& Khanna, 2000; Larsson, Bengtsson, Henriksson \& Sparks, 1998; Kale, Singh \& Perlmutter, 2000;) argues that collaboration can facilitate the creation of new knowledge, and not just the transfer of existing knowledge (e.g., Gulati, 1999; Powell, 1990; Powell et al., 1996). Work on networks (e.g., Dyer, 1996; Gulati, 1998; Nohria \& Eccles, 1992; Wasserman \& Galaskiewicz, 1994) and social capital (e.g., Bourdieu, 1993; Laclau \& Mouffe, 1985; Nahapiet \& Ghoshal, 1998), suggests that collaboration can affect the structure of interorganizational relationships, making some organizations more central. Similarly, work that focuses on the political aspects of collaboration (e.g., Burt, 1992; Hardy \& Phillips, 1998; Knights, Murray \& Willmott, 1993; Warren, Rose \& Bergunder, 1974) has shown how it can be an important way of sustaining or increasing influence over other organizations.

While all these literatures are concerned with the effects of collaboration, each tends to focus on a different kind of effect and different streams of literature rarely acknowledge each other. In particular, the business literature on alliances, joint ventures and networks rarely refers to studies of collaboration in the public and sectors or to the more critically oriented work on the politics of collaboration. Consequently, in this section, we attempt to integrate these different literatures to differentiate three broad types of effects, which we refer to as the strategic, knowledge creation and political effects of collaboration. 


\section{Strategic Effects of Collaboration}

One important effect of collaboration lies in its potential to build organizational capacities through the transfer or pooling of resources. In the strategy literature, in particular, many authors argue that a primary rationale for collaboration is the acquisition of resources through the direct transfer of assets, the sharing of key equipment, intellectual property, or personnel, and the transfer of organizational knowledge (Dyer \& Singh, 1998; Hamel et al., 1989). From this viewpoint, organizations are motivated to collaborate in order to acquire resources that they cannot develop internally, but which are needed to survive in a highly competitive environment (Powell et al., 1996). Of particular importance are resources that help the organization develop distinctive capacities (Barney, 1991; Ghemawat, 1986; Peteraf, 1993; Prahalad \& Hamel, 1990). Distinctiveness describes the degree to which a resource adds value to the organization's activities in a way that is distinct from its competitors and difficult to imitate (Prahalad \& Hamel, 1990; Wernerfelt, 1984). To the extent that capacities are distinctive, they form the basis for core competencies that provide an organization with an enduring competitive advantage (Porter, 1996; Prahalad \& Hamel, 1990). Resources that lead to distinctive capacities therefore have the most value from a strategic point of view.

Strategic effects refer to the way in which collaboration helps organizations to improve their strategic performance by developing an enhanced competitive advantage (Galaskiewicz \& Zaheer, 1999; Gulati, Nohria \& Zaheer, 2000b) as a result of a variety of activities, including sharing resources, developing technological know-how, sharing knowledge, acquiring new distribution outlets, building a greater understanding of new markets, and securing access to scarce assets (e.g., Amara, 1990; Dyer, 1996; Gulati et al., 2000a). According to this view, collaboration is about working with partners to leverage existing resources of all kinds to provide 
maximum strategic benefit. Thus the strategic effects of collaboration are primarily about the pooling and transfer of resources of all kinds.

Research in the not-for-profit sector also effectively adopts a strategic view of collaboration when it argues that it builds capacities that enable organizations to address social problems more effectively (e.g., Gray, 1989; Huxham, 1996). In a parallel manner to the strategy literature, researchers of not-for-profit collaboration argue that it is the pooling of resources and knowledge that leads to the solution of otherwise insoluble problems (Trist, 1983). The reasons for collaborating are clear: organizations should collaborate to gain access to combinations of resources that produce new or improved capabilities that allow organizations to do things they could not do alone. While these organizations do not face market pressures, they still compete for funding, clients and government endorsement, and the acquisition of distinctive resources still has a "competitive” advantage.

In sum, the development of capacities within organizations is an important potential effect of interorganizational collaboration. The key to these strategic effects is the extent to which the new capacities are distinctive and consequently provide a competitive advantage to the organization. Thus, our first research question links interorganizational collaboration to organizational capacity building.

Research Question 1: What characteristics of collaboration are associated with the acquisition of distinctive resources?

\section{Knowledge Creation Effects of Collaboration}

Many writers have examined how collaboration leads to some form of organizational learning (e.g., Dodgson, 1996; Inkpen \& Crossan, 1995; Kogut, 1988; Levinson \& Asahi, 1995; Lyles, 1988). In some cases, researchers discuss such learning in terms of knowledge sharing and 
transfer (e.g., Dyer \& Nobeoka, 2000; Grant \& Baden-Fuller, 1995; Kale et al., 2000; Mowery, Oxley \& Silverman, 1996). In this case, collaboration helps organizations "to better utilize strategic alliances as vehicles for learning new technologies and skills from their alliance partners” (Lei \& Slocum, 1992: 81). In this case, learning in a collaboration is about learning from a partner and the collaboration has served its purpose once the necessary organizational knowledge has been successfully transferred.

But while collaboration can facilitate the transfer of existing knowledge from one organization to another, it can also create new knowledge that neither of the collaborators previously possessed (e.g., Gulati, 1999; Mowery et al., 1996). The importance of knowledge creation has, in particular, been noted by researchers who have studied innovation in inter-firm alliances from a social constructivist perspective (Powell et al., 1996). This stream of literature grows out of a theoretical perspective that sees knowledge as a property of communities of practice (Brown \& Duguid, 1991; Hendry, 1996; Larsson et al., 1998) or networks of collaborating organizations (Powell \& Brantley, 1992), rather than as resource that can be generated and possessed by individuals.

Knowledge creation occurs in the context of a community, one that is fluid and evolving rather than tightly bound or static ... Sources of innovation do not reside exclusively inside firms; instead, they are commonly found in the interstices between firms, universities, research laboratories, suppliers and customers (Powell et al., 1996, p. 121).

In other words, networks of collaborating organizations are an important source of knowledge creation. Moreover, knowledge is not simply a resource that can be transferred from organization 
to organization; rather, new knowledge grows out of the sort ongoing social interaction that occurs in ongoing collaborations.

Following the work of Powell et al. (1996) we believe that it is useful to differentiate between knowledge transfer, which we categorize as a strategic effect, and the knowledge creation effects of collaboration. From the perspective of the knowledge creation view, the more collaborative ties an organization has, and the greater the diversity of its partners, the more likely it will be successful at generating new knowledge (Powell et al., 1996; Simonin, 1997). Collaboration thus emerges from a series of ongoing, informal and unplanned relationships (Hakansson, 1990; Von Hippel, 1988). This approach challenges some of the strategic work that emphasizes the importance of a formal agreement with clearly identified goals, highly rational partner selection criteria, specified controls for monitoring performance, and a clear understanding of the termination arrangements (Powell et al., 1996).

In summary, this body of literature sees collaboration as somewhat different from the strategic literature. Collaboration is not a means of compensating for the lack of internal skills, nor is it a series of discrete transactions; rather it is a source of ongoing, synergistic partnering leading to knowledge creation (Powell et al., 1996). This leads to a second research question regarding the relationship between the nature of collaboration and the likelihood of knowledge creation, versus strategic, effects.

Research Question 2: What characteristics of collaboration are associated with the creation of knowledge?

\section{The Political Effects of Collaboration}

Network theory (e.g., Burt, 1982; Nohria \& Eccles, 1992; Wasserman \& Galaskiewicz, 1994) conceptualizes organizations as embedded (Dacin, Ventresca \& Beal, 1999; Granovetter, 
1985; Kogut, 2000; Rowley, Behrens \& Krackhardt, 2000) in networks of linkages, which both facilitate and constrain their actions and shape their interests (Nohria \& Gulati, 1992). Proponents of a network perspective argue that the most significant aspect of an organization's environment is the set of other organizations with which it interacts and the pattern of relationships among them. As Barley, Freeman and Hybels (1992, p. 313) argue: "not only are the organizations suspended in multiple, complex, and overlapping webs of relationships, the webs are likely to exhibit structural patterns that are invisible from the standpoint of a single organization caught in the tangle.” These structural patterns, and the positions of organizations within them, have a significant impact on the degree to which organizations are able to control their own actions and influence those of others.

A critical aspect of an organization's location in a network is its centrality - the degree to which it is directly and indirectly connected to other organizations and the degree to which other organizations are connected through it. Galaskiewicz (1979, p. 151) argued that centrality is important because organizational power is not so much a function of its direct control of resources, but rather, "the set of resources that actors [can] mobilize through their existing set of social relationships”. Bourdieu $(1977,1986,1993)$ has examined in some depth the relationship between positions in fields and the resources that accrue to the occupants of those positions. He argues that fields "present themselves synchronically as structured spaces of positions (or posts) whose properties depend on the position within these spaces” (1993, p. 72). For Bourdieu (1986), the position of an actor within a field is associated with specific forms and amounts of capital (economic, social and cultural), which, like the idea of centrality in network analysis, allow the actor to direct their own lives and influence others. The idea of positions endowing occupants with power and influence is also prominent in Laclau and Mouffe's (1985) analysis of 
hegemony. Within interorganizational networks, nodal points exist from where actors not only control the flow of critical resources, and especially information, but also shape the meanings attached to those resources (also see Callon (1986) on obligatory passage points).

Collaborations necessarily change the network of interactions between organizations for the duration of the collaborative relationship. However, the effects of the collaboration may be much broader than the single collaborative relationship and may endure beyond the life of the collaboration. For instance, a collaboration may generate ties between organizations that are not directly involved in the collaboration or may work to change the broad pattern of resource and information flows across the network. Therefore the network transformation effects of a collaboration may be much greater than the addition of a single link between two or more collaborating organizations for a finite period. Consequently the effects of a collaboration on the network position of an organization may vary significantly (see, for example, Dyer, 1996; Gulati, 1998; Wasserman \& Galaskiewicz, 1994).

Work that adopts a political perspective on interorganizational relations has also pointed out that one advantage of collaboration can be the acquisition of power and influence (e.g., Knights et al., 1993). Particularly when partners have different goals, values and beliefs (Waddock, 1989) and when the distribution of power between them is unequal (Gray \& Hay, 1986), collaboration may be a means to protect specific organizational interests. For example, more powerful stakeholders may force collaboration on weaker players to control them; or they may cooperate with other powerful allies to prevent opponents from reconstituting the field or domain in which they operate (Hall \& Spencer-Hall, 1982; Hasenfeld \& Chesler, 1989; Rose \& Black, 1985; Warren et al., 1974). In other words, collaboration may represent moves by 
organizations to protect their privileged positions and disadvantage other organizations (Gricar \& Brown, 1981; Hardy \& Phillips, 1998).

In sum, the political effects of collaboration are a potentially important outcome. Organizations may engage in collaboration to increase their centrality and the degree of their influence over other organizations. Our third research question addresses this relationship between collaboration and influence.

Research Question 3: What characteristics of collaboration are associated with changes in interorganizational influence?

\section{METHODOLOGY}

We chose to investigate the question of the effects of collaboration through a qualitative study of the collaborative activities of Mère et Enfant (Palestine). We adopted a qualitative, multi-case comparative research design based on our primary aim of theory development. The use of a qualitative methodology was intended to provide rich data that could facilitate the generation of theoretical categories that could not have been derived satisfactorily from existing theory (Van Maanen, 1979). In comparing across cases, the unit of analysis on which we focused was the collaboration, rather than the organization: we examined multiple instances of collaboration by a single organization in order to assess the impact of different characteristics of collaboration without the confounding impact of organizational characteristics. In developing and implementing this research design, a central goal was to achieve a rigorous and transparent methodology from which the logic of the resulting grounded theory could clearly be traced. In order to achieve this rigor and transparency, our data analysis focuses on systematic coding and cross-case comparison, rather than on the more traditional qualitative approaches that emphasize the presentation and interpretation of extended narratives (e.g., Lincoln \& Guba, 1985). 
Mère et Enfant is an international NGO that operates in a number of different countries. Its headquarters are located in Europe, and it is funded primarily by its home country's government. Its charter commits the organization to work on behalf of the neediest of the world's children, regardless of gender, race, nationality or other considerations. It works with children as members of families within the community rather than as individuals, emphasizing prevention and education. It is committed to sharing its knowledge and to empowering the community it serves.

Our interest is in one particular "branch" of Mère et Enfant - Mère et Enfant (Palestine) that operates in the West Bank and Gaza (although for the sake of brevity, we will refer to the branch as Mère et Enfant for the remainder of the paper). The emphasis in this region is on child nutrition: the reduction of infant mortality; the improvement of the nutritional status of children; the provision of nutritional rehabilitation to malnourished children; and the raising of awareness of the importance of good nutrition. It treats children directly by providing medical and nutritional services in clinics in the West Bank and Gaza and uses an outreach program to provide services in rural communities. It provides training to health care professionals in such areas as diarrhea management, breast-feeding, and safe weaning. It conducts research into the nutritional status and food security and other matters related to the health of Palestinian children. Finally, it provides information and education about nutrition and poverty.

\section{Data Collection}

Our primary contact during the data collection process was the manager of Mère et Enfant. The manager is an expatriate employee who manages the 60 individuals employed by Mère et Enfant in this region, all of whom are Palestinian except for one British nutritionist. Since taking up his position in 1993, the manager of Mère et Enfant had embarked on an explicit 
strategy of collaboration with a variety of organizations. While these collaborations (see Table 1 for summaries) differed in terms of their magnitude and impact, together they formed a broad strategy encompassing a collaborative orientation that was intended to enhance Mère et Enfant's ability to raise funds and deliver services related to nutrition.

Insert Table 1 about here

We began our study with an exploratory visit to Palestine by one of the authors and an introductory interview with the manager to ascertain the extent of collaborative activity in which the organization was involved and to secure his agreement to participate in the study. This was followed up by a second, longer interview with the manager to provide the necessary background information on Mère et Enfant and an overview of the individual collaborations. Then, two of the authors traveled to Palestine for two weeks during which most of the interviews were carried out. On our arrival in Palestine, we began with another long interview with the manager and visits to each of the offices of Mère et Enfant in Bethlehem, Hebron and Gaza. He also made available a range of documentation including memos, organizational newsletters, organizational charts, year-end reports, minutes of meetings, funding proposals, and many other documents.

In addition to the manager, we also interviewed employees in the organization, members of the advisory board of Mère et Enfant, relevant members of the Palestinian National Authority, and some Palestinian managers in the organization. Once we had a clear idea of the history and current activities of the organization we began to investigate the collaborations in which the organization was involved. With the help of the manager, we arranged interviews with at least one representative, who played an active role in the collaboration, of each of the organizations that had collaborated with Mère et Enfant since the manager's arrival. Interviews were conducted 
in English, lasted between one and two hours, were semi-structured, recorded and transcribed. We conducted one interview by telephone as the representative was not in the country at the time of our visit. The interviews focused on the history and the outcomes of the collaboration for the participants and for the institutional field. We also collected a range of documents from our interviewees in order to better understand their organizations and the nature of the collaborations with Mère et Enfant. We concluded the field trip with a summary interview with the manager.

\section{Data Analysis}

The data analysis for this article consisted of three stages: (1) developing summaries of each collaboration; (2) coding the summaries for the characteristics and effects of collaboration; and (3) analyzing the pattern of relationships among the conceptual categories.

In the first stage of the data analysis, we developed a summary of each collaboration that Mère et Enfant was engaged in over a four year period (Eisenhardt \& Bourgeois, 1988). ${ }^{3}$ These summaries were based on all of the raw data collected for each collaboration (i.e., interviews and archival documentation). From this data, we constructed a chronological description of each collaboration, describing how it came about, when it happened, who was involved, and its major outcomes. We confirmed that we had understood events correctly by checking the summaries with the manager of Mère et Enfant. We used these descriptions as a basis for more focused summaries, in which we reorganized the information around the themes central to this paper the characteristics and effects of collaboration. The resulting summaries constituted descriptions that thoroughly covered the relevant characteristics of the collaborations and their effects.

The second stage of analysis involved coding each summary with respect to its characteristics and effects. This was a highly iterative procedure (Glaser \& Strauss, 1967) that involved moving between the summaries, existing theory, and the raw data. From the summaries, 
we initially advanced first order descriptions (Van Maanen, 1979) based on broad categories that were developed from the theory. For example, we characterized the different collaborations to the extent to which they generated new practices, technologies and rules or built sustainable and distinctive capacities, using existing categories from institutional theory and strategic management. We then refined these categories by tracing patterns and consistencies (e.g., Bailyn, 1977; Mintzberg, 1979): we scrutinized interviews and documentation, and revised and elaborated our initial ideas, as additional evidence suggested modifications or elimination. The analysis continued with this interplay between the data and the emerging patterns until the patterns were refined into adequate conceptual categories (Bailyn, 1977; Eisenhardt, 1989; Sutton \& Callahan, 1987). We refined the categories and developed more specific conceptual codes to capture the key commonalties and differences across the collaborations. Following Miles and Huberman (1984) and Sutton and Callahan (1987), we provide cross-case display tables to present similarities and differences in the conceptual categories across cases (Table 2 below). We concluded this stage of the data analysis by checking our coding and analysis with the manager of Mère et Enfant to ensure that the various categories and codings were consistent with his recollection and understanding of events.

The third stage of the data analysis involved a cross-case, comparative analysis to examine the relationships among the theoretical categories. Specifically, we were interested in the relationships between the characteristics of collaboration and its effects. As part of this process, we used the constant comparative method (Glaser \& Strauss, 1967) to modify and simplify the conceptual categories, constructed in stage two, to create simpler, more robust categories that could be more clearly related to one another. Based on the patterns evident in our stage two analysis, we collapsed the various categories describing characteristics of collaboration into two 
broader dimensions, which we refer to as involvement and embeddedness, and rated each collaboration as low, medium or high on each. Finally, we rated each collaboration as either high, medium or low on each of the three effects - strategic, knowledge creation and political. The results allowed us to discern patterns linking the characteristics and effects of collaboration, the details of which are explained in more detail in the following section.

\section{RESULTS AND DISCUSSION}

In this section, we first develop a set of dimensions that describe the characteristics of Mère et Enfant's collaborations. We then explore the various effects of these collaborations, and develop theoretical propositions that relate those effects to the characteristics of collaboration.

\section{Characteristics of Collaboration}

In order to examine the characteristics of collaboration, we build on our earlier work (Lawrence, Hardy, \& Phillips, forthcoming) where we applied DiMaggio and Powell’s (1983) work on structuration to develop three dimensions that differentiated Mère et Enfant's collaborations. The three dimensions were: (1) the pattern of interactions among collaborating organizations; (2) the structure of the coalition formed by collaborating partners; and (3) the pattern of information-sharing among collaborating partners. We applied these three dimensions to the empirical data (see Table 2 for a summary).

Insert Table 2 about here

First, collaboration, by its very nature, involves interactions between collaborating organizations (e.g., Huxham, 1996), and it sometimes embodies new interactions between collaborating participants and other parties outside the collaboration itself (Lawrence \& Hardy, 1999). In examining each collaboration, we identified differences in the depth and scope of 
interaction. The depth of interactions ranged from shallow, where interactions were restricted to the Mère et Enfant manager and his counterpart, to deep, where the interactions extended to other personnel from Mère et Enfant and the collaborating organization. The scope of interactions ranged from narrow, where Mère et Enfant interacted only with its collaborating partner to broad, where Mère et Enfant interacted with third parties during the collaboration.

Second, collaboration involves a variety of structures in terms of the new coalitions that may be formed. This aspect of collaboration has been noted, for example, in the literature on strategic alliances and joint ventures (Buckley \& Casson, 1988; Hennart, 1991; Kogut, 1991) and on government and voluntary sectors (e.g., Hardy \& Phillips, 1998). In analyzing Mère et Enfant's collaborative structures, we found the case of transactions, where the collaboration did not involve a new collaboration but, instead, resources were pooled among Mère et Enfant and its partners. In the case of partnerships, the collaboration was characterized by a new coalition in which Mère et Enfant and its partner worked together to carry out particular activities. Third, in the case of representation, the collaboration involved a new coalition in which the collaborating organizations represented each other's interests to outside parties.

Third, interorganizational collaboration allows organizations to exchange information and learn about the links and commonalties among them (e.g., Gray, 1989; Hamel et al., 1989; Inkpen \& Crossan, 1995; Levinson \& Asahi, 1995). From the collaborative activities of Mère et Enfant, we identified three patterns of information flow: unidirectional, where one of the collaborating organizations learned from the other; bi-directional, where all collaborating partners learned from each other; and multi-directional, where collaborating organizations and third parties learned from each other. 
We were then able to identify two aggregate dimensions to capture particular patterns in the nature of interactions, coalitions and information flows (see Table 2). First, focusing on the internal dynamics - the ways in which the participating organizations related to each other - we classified collaborations with (1) deep interactions, (2) partnerships, and (3) bilateral information flows as having high levels of involvement among collaborating partners. For example, in the collaboration with Médecins sans Frontièrs, a number of personnel from both organizations worked together. The organizations partnered to provide a multi-faceted approach to nutritional problems. Information flowed between the organizations as they learned from each other about the need for this service and how best to provide it. In other words, the two organizations were closely involved with each other as part of this collaboration.

Altogether, six collaborations exhibited deep interactions, partnerships, and bi-directional flows and were categorized as having high levels of involvement. Conversely, the collaborations with Oxfam and Pharmaciens sans Frontièrs exhibited none of these characteristics. For example, interactions with Pharmaciens sans Frontièrs were confined to two managers; there was no sharing of personnel; and Mère et Enfant learned little from its partner that it did not already know. These collaborations were characterized as having low levels of involvement.

Second, focusing on the external aspects - the degree to which the collaboration was enmeshed in interorganizational relationships - we characterized collaborations with (1) interactions with third parties, (2) representation and (3) multi-directional information flows as being highly embedded (Granovetter, 1985). In contrast to involvement, this dimension highlights the connection between the collaboration and the broader interorganizational network. For example, in the collaboration with Care International, the pattern of interactions was broad in the sense that it involved a third party, the Australian Embassy, as Care International intervened 
with the Embassy to secure the grant that funded the project. A new coalition was established as Mère et Enfant secured representation from Care - a much larger and well-known organization in its dealings with the Embassy. Information loads increased in a multi-directional manner when, as a result of the collaboration, not only Care, but also the Australian Embassy, learned about Mère et Enfant's work with women and children, as well as its expertise in accessing women in rural communities.

In total, three collaborations exhibited all these characteristics, and were classified as having high embeddedness. Four collaborations exhibited none of these characteristics and were classified as having low embeddedness. For example, interactions in the collaboration with the World Food Program were confined to the two organizations: the two organizations worked in partnership but neither took on a representational role for the other, and while information flowed between the two organizations, it did not spread to third parties. Finally, UNICEF exhibited broad interactions and multi-directional flows, but did not involve any representation, and was categorized as medium embeddedness.

\section{The Effects of Collaboration}

In this section, we examine the relationship between the degree of involvement and embeddedness of each collaboration and the nature of the effects of the collaboration. In this way we are able to develop a set of propositions linking collaboration to particular effects.

\section{Strategic Effects}

Powell et al. (1996) point out that the effects of collaboration are strategic when they enable organizations to secure resources that cannot be developed internally. Hamel et al. (1989) have emphasized the importance of acquiring resources that are distinctive and cannot easily be imitated, enabling the organization to differentiate itself from its competitors. In analyzing the 
degree to which the collaborations produced strategic effects, we therefore focused on the degree to which distinctive resources were acquired, improving the ability of collaborating partners to carry out their "core” business. So, for example, transferring skills in areas related to nutrition, counselling, and food distribution was counted as distinctive as far as Mère et Enfant’s was concerned since they increased the organization's capacity to carry out its mission of improving the nutrition of children in the region. In contrast, resources such as funds or buildings which, while important, were not considered distinctive and, hence, not strategic.

We rated six collaborations as high on strategic effects since they involved the acquisition of distinctive resources. For example, the collaborations with Medécins sans Frontièrs, Care International, UNICEF and the Oslo academics all transferred skills related to nutrition from the collaborating partner to Mère et Enfant. The collaborations with Peace on Earth and the World Food Program transferred distinctive skills from Mère et Enfant to their partners, which helped them carry out their work. In contrast, two collaborations - Oxfam and Pharmaciens sans Frontièrs provided Mère et Enfant with resources - funding and medicine that were important but which did not enhance either partner's distinctive competencies. Consequently, we classified these collaborations as low on strategic effects.

If we examine the relationship between strategic effects and the involvement and embeddedness associated with the collaborations, we see the following. High strategic affects are associated with high involvement and low, medium and high embeddedness. Low strategic effects are associated with low involvement and low embeddedness. Based on this pattern, it appears that the level of involvement among collaborators is the key dimension, while the level of embeddedness seems to have no significant effect on the strategic effects of collaboration. We suggest that involvement is necessary for "first order" learning, allowing collaborating partners 
to identify key resources and transfer knowledge that will enhance their core competencies and distinctive advantage. This relationship is summarized in the following proposition.

Proposition 1: Collaborations that have high levels of involvement will be positively associated with the acquisition of distinctive resources (strategic effects).

\section{Knowledge Creation Effects}

As Powell et al. (1996) have pointed out, the acquisition of resources and transfer of knowledge between collaborating partners is different than the creation of new knowledge. Knowledge creation occurs in the context of a community: it is not located so much inside organizations but rather between them. Accordingly, our analysis of knowledge creation focused on the degree to which Mère et Enfant's collaborations produced new knowledge and practices that diffused beyond the boundaries of the collaboration. High knowledge creation effects were associated with one collaboration - the Oslo academics - because new knowledge was diffused through multiple organizations and shaped the nature of nutritional policy. We categorized five collaborations as medium in terms of knowledge creation effects because new knowledge was diffused through one partner. For example, new knowledge and practices concerning the training of local Palestinians were acquired by Peace on Earth as a result of its collaboration with Mère et Enfant. This new knowledge was subsequently diffused by Peace on Earth in a subsequent collaboration with a local NGO involved in hydrology. Two collaborations failed to produce new knowledge and, as a result, were classified as low on knowledge creation.

If we examine the relationship between knowledge creation and the level of involvement and the degree of embeddedness, we see the following. First, low knowledge creation is associated with both low levels of involvement and low levels of embeddedness. Second, high 
knowledge creation is associated with high levels of involvement and embeddedness. Third, medium knowledge creation is associated with high levels of involvement and low, medium and high embeddedness. We suggest that both involvement and embeddedness are important for knowledge creation: high involvement facilitates the interorganizational learning necessary to create new knowledge, while embeddedness facilitates the transmission of this knowledge beyond the boundaries of the collaborative relationship to distribute learning more widely in the community. This relationship is summarized in the following proposition.

Proposition 2: Collaborations that have high levels of involvement and high levels of embeddedness will be positively associated with the creation of knowledge (knowledge creation effects).

\section{Political Effects}

Powell et al. (1996) argue that organizations must learn how to locate themselves in the central network positions that enable them to keep pace with competitive developments. This view draws our attention to the political effects of collaboration. Organizations may therefore engage in collaboration to increase their influence over other organizations (e.g., Hardy \& Phillips, 1998). In analyzing the political effects of each collaboration, we were interested in the way in which the collaboration increased the influence that partners had on the broader interorganizational relations of which they were a part.

In four cases, the collaboration produced no enduring change in interorganizational relationships. We labelled these four cases as Low in terms of political effects. In the remaining four cases, the collaboration produced new relationships between Mère et Enfant, but in different ways. In the case of Peace on Earth, Mère et Enfant was connected to a third party - the Japanese Embassy - but only through its partner since Peace on Earth was needed on an ongoing 
basis to represent its interests. So while, Mère et Enfant gained access to a potential new donor, its ability to influence this organization depended very much on the continued good will of its partner. We categorized these effects as medium. In three cases, the collaboration produced ongoing direct access to third parties, independently of its relationship to its partner. So, for example, as a result of the collaboration with Care International, Mère et Enfant was able to access the Australian Embassy directly; in the case of the Oslo collaboration, Mère et Enfant continued to influence the Ministry and other NGOs, even after the Oslo academics had returned home. In the case of the UNICEF collaboration, Mère et Enfant secured ongoing access to two hospitals, the Australian Embassy and the British Consulate.

If we examine the relationship between the political effects and the characteristics of the collaborations, we see the following. First, high political effects are associated with high involvement and high and medium embeddedness. Second, low political effects are associated with low or high involvement and low embeddedness. Third, medium political effects are associated with high involvement and high embeddedness. Since high levels of involvement are associated with low, medium and high political effects, involvement does not significantly change the degree of political influence. In contrast, high/medium political effects are associated with high/medium embeddedness, which seems to be a necessary, if not sufficient, condition to increase the influence of the organization in the local network. These relationships are summarized in the following proposition.

Proposition 3: Collaborations that are highly embedded will be positively associated with increases in influence (political effects). 


\section{CONCLUSION}

Based on the findings of our study of Mere et Enfant, we have argued that collaborations produce the strategic, knowledge creation, and influence effects predicted in the literature, but also that not all collaborations produce all three effects. There are important differences in the characteristics of the different collaborations that produce these effects. These differences, which we have summarized as involvement and embeddedness, are associated with the three types of effects in particular ways. Collaborations that are both involved and embedded are more likely to be associated with knowledge creation effects; those that are only involved are more likely to be associated with strategic effects; those that are only embedded are more likely to be associated with political effects.

Two limitations of the study need to be addressed. First, our data were based partly on retrospective accounts of the collaborations, which make it more difficult to examine some of the dynamics of the collaboration, particularly those that may be contentious or prone to reconstruction after the fact. To address this, we focused on aspects of the collaborations and their effects that are more easily recounted in an objective fashion (e.g., the individuals with whom there was contact, the activities engaged in), rather than the motives or perceptions of the participants at the time. The second limitation involves the focus on a small NGO operating in Palestine, which may invite questions of generalizability. Collaboration in the West Bank and Gaza undoubtedly has its own peculiarities stemming from the intense political, social and physical demands of the location that may interact significantly with the dynamics of an underresourced NGO. But, while there is a need for further research to test the propositions in different settings, there is no a priori reason to suggest that the model would not be more widely applicable. While not-for-profit organizations do not compete in the traditional sense, they do 
compete for funding, for clients and for government approval. Given these similarities between voluntary and business sectors, there is no reason why businesses would not benefit from collaboration in a similar way to Mère et Enfant.

Our study has a number of implications. First, it makes the important observation that there are inescapable tensions between knowledge creation and strategic effects. Being highly involved leads to strategic effects, but being simultaneously highly embedded leads to knowledge creation effects. The reason for this is clear from our research: while being embedded and involved produces new knowledge, it is also an inherently "leaky" kind of collaboration where the strategic benefits of the new knowledge are often quickly transmitted to other members of the network. The network as a whole may therefore be highly innovative and competitive, but this may be at the expense of individual organizations who are forced to "share" this knowledge. This has important implications for managers: if they collaborate to gain strategic advantage, then they may limit new knowledge; if they collaborate to maximize knowledge creation, they will not necessarily maximize strategic effects (c.f., Brown \& Hendry, 1997/1998), although the collaboration may function to make one knowledge creation alliance more competitive than another.

Second, our findings also challenge some of the conventional wisdom about establishing a successful collaboration. From the strategy perspective, successful collaborations have clear goals, partner selection criteria, performance monitoring and termination arrangements. They are also discrete events, carefully circumscribed to protect competitive advantage and safeguard against opportunistic partners. The knowledge creation view, in contrast, suggests that the advantages of collaboration extend beyond any formal contract and that the greatest innovation may emerge from ongoing, informal and unplanned relationships. The important point is that 
there are tradeoffs between different kinds of effects and what forms of collaboration are most appropriate for a particular situation requires that tradeoffs be made. Some firms may be tempted to opt for strategic effects and protect their competitive advantage but, as Powell et al. (1996) have pointed out, this may be a particularly shortsighted view in industries where knowledge is rapidly changing. In the longer term, organizations in these "knowledge-based" industries may be better advised to collaborate for knowledge creation. This tension is equally relevant to voluntary organizations: if the aim is to empower communities and resolve intractable, illdefined social problems, then surely the aim should be to collaborate for knowledge creation.

Third, our study also has important methodological implications in that it demonstrates the utility of fine-grained, qualitative approaches to the study of interorganizational relationships. Much of the contemporary research has been dominated by large-scale, quantitative methods that track extensive networks across an industry over time. There is, however, also much to be gained from examining more localized dynamics that can be dealt with in a more intensive fashion. Furthermore, we have tried to demonstrate that the use of qualitative research methods does not necessarily mean abandoning a systematic and transparent approach to data analysis. By carefully and rigorously analyzing multiple case studies, important insights can be gained which are inaccessible by more quantitative methods. For example, our findings are useful in clarifying exactly what aspects of collaboration are important and in providing a richer understanding of what they mean for managers interested in establishing collaborations. While the literature has indicated that "intense” collaboration are more likely to produce learning, this study provides some insight as to how such collaborations might be set up to achieve such intensity i.e., with deep interactions that engage a number of employees from different organizations working together, a partnership between collaborating partners, and strong flows of information between 
organizations. Similarly, while the network literature suggests that collaborations should increase "centrality", this study shows that this can be achieved by broad interactions, third party involvement and multi-lateral information flows. It also indicates that increasing influence can be achieved not merely by increasing the number of ties to collaborating partners, but by establishing collaborations that produce direct, enduring connections to third party organizations. Finally, by providing insight into the relationship between particular kinds of collaboration and a range of collaborative effects, the study suggests that a more holistic approach to the study of interorganizational collaboration is necessary. Researchers have tended to consider different types of collaborations, and different types of collaborative outcomes, largely in isolation. Our results point to the importance of developing a better understanding of the range of effects that collaboration can have, of the relationship between different kinds of effects, and of the particular dimensions of collaboration that may produce these effects. More work is needed to integrate the different streams of literature and develop a more integrated and in-depth understanding of collaboration. 


\section{REFERENCES}

Afuah, A. (2000). 'How much do your co-opetitors' capabilities matter in the face of technological change'. Strategic Management Journal, 21, 3, 397-404.

Amara, R. (1990). 'New directions for innovation'. Futures, 22, 2, 142-152.

Anand, B. and Khanna, T. (2000). 'Do firms learn to create value? The case of alliances'. Strategic Management Journal, 21, 3, 295-315.

Bailyn, L. (1977). 'Research as a cognitive process: Implications for data analysis'. Quality and Quantity, 11, 97-117.

Barley, S., Freeman, J. and Hybels, R. (1992). 'Strategic alliances in commercial biotechnology'. In Nohria, N. and Eccles, R. (Eds.), Networks and Organizations: Structure, Form and Action. Boston, MA: Harvard University Press, 311-347.

Barney, J. B. (1991). 'Firm resources and sustained competitive advantage'. Journal of Management, 17, 1, 99-120.

Bourdieu, P. (1977). Outline of a Theory of Practice. Cambridge: Cambridge University Press.

Bourdieu, P. (1986). 'The forms of capital'. In Richardson, J. G. (Ed.), Handbook of Theory and Research for the Sociology of Education. New York: Greenwood Press, 241-258.

Bourdieu, P. (1993). Sociology in Question. London: Sage.

Brown, J. and Hendry, C. (1997/1998) 'Industrial districts and supply chains as vehicles for managerial and organizational learning', International Studies of Management and Organization, 27, 127-157.

Brown, J. S. and Duguid, P. (1991). 'Organizational learning and communities-of-practice: Toward a unified view of working, learning, and innovation'. Organization Science, 2, 4057.

Buckley, P. J. and Casson, M. (1988). 'A theory of cooperation in international business'. In Contractor, F. and Lorange, P. (Eds.), Cooperative Strategies in International Business. Lexington, Mass: Lexington Books, 31-54.

Burt, R. (1982). Toward a Structural Theory of Action. New York: Academic Press.

Burt, R. (1992). Structural Holes: The Social Structure of Competition. Harvard University Press: Cambridge MA.

Callon, M. (1986). 'Some elements of a sociology of translation: Domestication of the scallops and the fisherman of St. Briene Bay'. In Law, J. (Ed.), Power, Action and Belief: A Sociology of Knowledge. London: Routledge.

Dacin, M. T., Ventresca, M. J. and Beal, B. D. (1999). 'The embeddedness of organizations: Dialogue and directions'. Journal of Management, 25, 3, 317-356.

DiMaggio, P. J. and Powell, W. W. (1983). 'The iron cage revisited: Institutional isomorphism and collective rationality in institutional fields'. American Sociological Review, 48, 147160.

Dodgson, M. (1996). ‘Learning, trust, and technological collaboration’. Human Relations, 46, 77-95.

Dyer, J. (1996). 'Specialized Supplier Networks as a Source of Competitive Advantage: Evidence from the Auto Industry'. Strategic Management Journal, 17, 4, 271-291.

Dyer, J. and Nobeoka, K. (2000). 'Creating and Managing a High-Performance KnowledgeSharing Network: The Toyota Case'. Strategic Management Journal, 21, 3, 344-368. 
Dyer, J. and Singh, H. (1998). 'The Relational View: Cooperative Strategies and Sources of Interorganizational Competitive Advantage’. Academy of Management Review, 23, 4, 660679.

Eisenhardt, K. M. (1989). 'Building theories from case study research'. Academy of Management Review, 14, 532-550.

Eisenhardt, K. M. and Bourgeois, L. J. (1988). 'Politics of strategic decision making in highvelocity environments: Toward a midrange theory’. Academy of Management Journal, 31, 737-770.

Galaskiewicz, J. (1979). Exchange Networks and Community Politics. Beverly Hills, CA: Sage.

Galaskiewicz, J. and Zaheer, A. (1999). 'Networks of competitive advantage' In S. Andrews and D. Knoke (eds.) Research in the Sociology of Organizations, JAI Press: Greenwich, CT., 237-261.

Ghemawat, P. (1986). 'Sustainable advantage'. Harvard Business Review, September-October, 53-58.

Glaser, B. and Strauss, A. (1967). The Discovery of Grounded Theory: Strategies for Qualitative Research. Chicago: Aldine.

Granovetter, M. (1985). 'Economic action and social structure: the problem of embeddedness'. American Journal of Sociology, 91, 481-510.

Grant, R. and Baden-Fuller, C. (1995). 'A knowledge-based theory of inter-firm collaboration'. Academy of Management Journal, 38, 17-39.

Gray, B. (1989). Collaborating. San Francisco: Jossey-Bass.

Gray, B. and Hay, T. M. (1986). 'Political limits to interorganizational consensus and change'. The Journal of Applied Behavioral Science, 22, 2, 95-112.

Gricar, B. and Brown, L. D. (1981). 'Conflict, Power and Organization in a Changing Community’. Human Relations, 34, 877-893.

Gulati, R. (1998). 'Alliances and networks'. Strategic Management Journal, 19, 4, 293-317.

Gulati, R. (1999). 'Network location and learning: The influence of network resources and firm capabilities on alliance formation'. Strategic Management Journal, 20, 5, 397-420.

Gulati, R., Nohria. N. Akbar, Z. (2000a) 'Guest editors' introduction to the special issue: Strategic networks’. Strategic Management Journal, 21, 3, 203-215.

Gulati, R., Nohria. N. Akbar, Z. (2000b). 'Strategic networks'. Strategic Management Journal, 21, 3, 199-201.

Hakansson, H. (1990). ‘Technological collaboration in industrial networks'. Engineering Management Journal, 8, 371-379.

Hall, P. M. and Spencer-Hall, D. A. (1982). 'The social conditions of the negotiated order'. Urban Life, 11, 3, 328-349.

Hamel, G. (1991). 'Competition for competence and inter-partner learning within international strategic alliances’. Strategic Management Journal, 12, 83-103.

Hamel, G., Doz, Y. L. and Prahalad, C. K. (1989). 'Collaborate with your competitors - and win’. Harvard Business Review, January-February, 133-139.

Hardy, C. and Phillips, N. (1998). 'Strategies of engagement: Lessons from the critical examination of collaboration and conflict in an interorganizational domain'. Organization Science, 9, 2, 217-230.

Hasenfeld, Y. and Chesler, M. A. (1989). 'Client empowerment in the human services: Personal and professional agenda’. Journal of Applied Behavioral Science, 25, 499-521. 
Heide, J. (1994). 'Interorganizational governance in marketing channels'. Journal of Marketing, 50, 40-51.

Hendry, C. (1996). 'Understanding and creating whole organizational change through learning theory'. Human Relations, 49, 5, 621-641.

Hennart, J. F. (1988). 'A transaction cost theory of equity joint ventures', Strategic Management Journal, 9, 361-374.

Hennart, J.F. (1991). 'The transaction cost theory of joint ventures: An empirical study of Japanese subsidiaries in the United States'. Management Science, 37, 4, 483-497.

Huxham, C. (1996). Creating Collaborative Advantage. London: Sage.

Inkpen, A. C. and Crossan, M. M. (1995). 'Believing is seeing: Joint ventures and organization learning'. Journal of Management Studies, 32, 5, 595-618.

Jehn, K. A. (1997) 'A qualitative analysis of conflict types and dimensions in organizational groups'. Administrative Science Quarterly, 42, 530-557.

Kale, P., Singh, H., Perlmutter, H. (2000). 'Learning and protection of proprietary assets in strategic alliances: Building relational capital'. Strategic Management Journal, 21, 3, 217237.

Knights, D., Murray, F. and Willmott, H. (1993). 'Networking as knowledge work: A study of strategic interorganizational development in the financial services industry'. Journal of Management Studies, 30, 6, 975-995.

Kogut, B. (1988). 'Joint ventures: Theoretical and empirical perspectives'. Strategic Management Journal, 9, 319-332.

Kogut, B. (1991). 'Joint ventures and the option to expand and acquire'. Management Science, 37, 19-33.

Kogut, B. (2000). 'The Network as knowledge: Generative rules and the emergence of structure'. Strategic Management Journal, 21, 3, 405-425.

Laclau, E. and Mouffe, C. (1985). Hegemony and Socialist Strategy. London: Verso.

Larsson, R., Bengtsson, L., Henriksson, K., and Sparks, J. (1998). 'The interorganizational learning dilemma: Collective knowledge development in strategic alliances’. Organization Science, 9, 3, 285-305.

Lawrence, T. B. and Hardy, C. (1999). 'Building bridges for refugees: Toward a typology of bridging organizations'. Journal of Applied Behavioral Science, 35, 1, 48-70.

Lawrence, T. B., Hardy, C. and Phillips, N. (forthcoming) 'Institutional effects of interorganizational collaboration: The emergence of proto-institutions', Academy of Management Journal.

Lawrence, T. B., Phillips, N. and Hardy, C. (1999). 'Watching whale-watching: A relational theory of organizational collaboration'. Journal of Applied Behavioral Science, 35, 4, 479502.

Lei, D. and Slocum, J. W. (1992). 'Global strategy, competence building and strategic alliances’. California Management Review, 35, 1, 81-97.

Levinson, N. and Asahi, M. (1995). 'Cross-national alliances and interorganizational learning'. Organizational Dynamics, 24, 2, 50-63.

Lincoln, Y. S. and Guba E. G. (1985). Naturalistic Inquiry. Newbury Park, CA: Sage.

Lyles, M. A. (1988). 'Learning among joint venture sophisticated firms'. Management International Review, 28, (special issue), 69-86.

Miles, M. and Huberman, A. (1984). Qualitative Data Analysis. Beverly Hills, CA: Sage. 
Milne, G. R., Iyer, E. S. and Gooding-Williams, S. (1996). 'Environmental organization alliance relationships within and across nonprofit, business and government sectors'. Journal of Public Policy and Marketing, 15, 2, 203-215.

Mintzberg, H. (1979). 'An emerging theory for direct research'. Administrative Science Quarterly, 24, 582-589.

Mowery, D., Oxley, J. and Silverman, B.S. (1996). 'Strategic alliances and interfirm knowledge transfer’. Strategic Management Journal, 17, 1, 77-91.

Nahapiet, J. and Ghoshal, S. (1998). 'Social capital, intellectual capital and the organizational advantage'. Academy of Management Review, 23, 2, 242-266.

Nohria, N. and Eccles, R. G. (1992). Network and Organizations: Structure, Form and Action. Boston, MA: Harvard Business School.

Nohria, N. and Gulati, R. (1994). 'Organizations and environment'. In Smelser, N. and Swedberg, R. (Eds), Handbook of Economic Sociology. Princeton, NJ: Princeton University Press.

Peteraf, M. A. (1993). 'The cornerstones of competitive advantage'. Strategic Management Journal, 14, 33-46.

Phillips, N., Lawrence, T. B. and Hardy, C. (2000). 'Interorganizational collaboration and the dynamics of institutional fields'. Journal of Management Studies, 37, 1, 23-45.

Porter, M. E. (1996). 'What is strategy?'. Harvard Business Review, November-December: 6178.

Powell, W. W. (1990). 'Neither market nor hierarchy: Network forms of organization'. In Staw, B. M. and Cummings, L. L. (Eds.), Research in Organizational Behavior, Greenwich, CT: JAI Press, 295-336.

Powell, W. W. and Brantley, P. (1992). 'Competitive cooperation in biotechnology: Learning through networks?’. In Nohria, N. and Eccles, R. G. (Eds) Network and Organizations: Structure, Form and Action, Boston, MA: Harvard Business School, 366-394.

Powell, W. W., Koput, K. W., and Smith-Doerr, L. (1996). 'Interorganizational collaboration and the locus of innovation: Networks of learning in biotechnology'._Administrative Science Quarterly, 41, 1, 116-146.

Prahalad, C. K., and Hamel, G. (1990). 'The core competence of the corporation'. Harvard Business Review, 68, 3, 79-91.

Rose, S. M. and Black, B. L. (1985). Advocacy and Empowerment: Mental Health Care in the Community. Boston: Routledge and Kegan Paul.

Rowley, T., Behrens, D. and Krackhardt, D. (2000). 'Redundant governance structures: An Analysis of structural and relational embeddedness in the steel and semiconductor industries’ Strategic Management Journal, 21, 3, 369-386.

Simonin. B. (1997). 'The importance of collaborative know-how: An empirical test of the learning organization’. Academy of Management Journal, 40, 5, 1150-1174.

Sutton, R. and Callahan, A. (1987). 'The stigma of bankruptcy: Spoiled organization image and its management'. Academy of Management Journal, 30, 405-436.

Teece, D. (1986). 'Profiting from technological innovation: Implications for integration, collaboration, licensing, and public policy', Research Policy, 15, 785-805.

Trist, E. (1983). 'Referent organizations and the development of interorganizational domains'. Human Relations, 36, 269-284. 
Van Maanen, J. V. (1979). 'The fact of fiction in organizational ethnography'. Administrative Science Quarterly, 24, 539-550.

Von Hippel, E. (1988). Sources of Innovation. New York: Oxford University Press.

Waddock, S. A. (1989). 'Understanding social partnerships: An evolutionary model of partnership organizations’. Administration and Society, 21, 78-100.

Warren, R. L., Rose, S. and Bergunder, A. (1974). The Structure of Urban Reform. Lexington. MA: DC Heath.

Wasserman, S. and Galaskiewicz, J. (1994). Advances in Social Network Analysis: Research in the Social and Behavioral Sciences. Thousand Oaks, CA: Sage.

Wernerfelt, B. (1984). 'A resource based view of the firm’. Strategic Management Journal, 5, 171-180.

Williamson, O. E. (1991). 'Comparative economic organization: The analysis of discrete structural alternatives’. Administrative Science Quarterly, 36, 269-296. 


\section{TABLE 1: SUMMARY OF COLLABORATIONS INVOLVING MÈRE ET ENFANT}

Médecins sans completed during the period of study

Care International:

commenced and completed during the period of study

University

of Oslo: commenced

during the period of study

and ongoing Frontièrs: commenced and

Médecins sans Frontièrs is an international NGO whose membership comprises primarily doctors and health workers who offer assistance to populations in distress from natural and man-made disasters. Médecins sans Frontièrs and M\&E collaborated in the development of a mental health care program designed to address the psychological problems of mothers that were often associated with malnutrition among Palestinian children. Two psychologists, employed and funded by Médecins sans Frontièrs worked in M\&E's Hebron clinic for a year. As mothers came for nutritional advice, they were able to access counseling and other psychological support. In addition, the psychologists used M\&E's community outreach team to contact women who were unable to attend the Hebron clinic. At the end of the year, the project involved more than 200 families. In addition, the psychologists trained M\&E's staff in mental health issues, and longer-term plans were being put in place to train a Palestinian community health worker to take over some of the work. The combination of mental health care and nutritional education was new for Medécins sans Frontièrs which had previously not collaborated to apply its specialist knowledge to a substantive area. The experience with M\&E led to a subsequent collaboration, based on the same model, with another NGO dealing with children who had been in jail.

M\&E initiated a collaboration with Care International, which delivers relief assistance to people in need and long-term solutions to global poverty, to help women in the community to develop income generation projects. Care first secured funding of $\$ 10,000$ from the Australian Embassy for the initiative, and then helped train M\&E personnel in setting up the projects, such as raising rabbits and goats or making clothes, with women in the community and then monitoring their success. The initial micro-credit scheme was modified during the course of the collaboration to become an income generation scheme in order to extend access to a wider group of women who could not repay the original loan and who had no previous experience of income generation. By collaborating with M\&E, Care developed strategies for accessing impoverished women in isolated rural communities and implemented them in a subsequent collaboration with a local NGO.

The University of Oslo's School of Nutrition came to Gaza to offer its services to the Ministry of Health as part of an ongoing initiative with the Nutrition Council of Norway to develop a nutrition and food policy for the region. A collaboration was established with M\&E to coordinate this relationship, which included training of ministry officials by M\&E and the Oslo academics. In addition, a workshop was organized to develop strategies for food safety and control, nutrition, chronic diseases, clinical nutrition, and food security. The Oslo academics and 56 members of the Ministry of Health, other ministries in the PNA and major NGOs in the region participated in the workshop. Following the workshop, M\&E drafted a nutritional policy for the region and plans for a new department to deal with food security and nutrition in the Ministry of Health, which were subsequently approved by the Ministry of Health in the Palestinian National Authority. As a result of the collaboration, As a result of the workshop, M\&E is consulted by the Ministry of Health, other ministries and NGOs on nutritional matters. M\&E also secured access to the Norwegian Embassy which, in turn, led to contacts to other embassies, and to other Norwegian NGOs, as a result of which M\&E secured a 3-year grant from a Norwegian NGO to fund a community nutrition program.

Peace on Earth: Peace on Earth is a Japanese charity that collaborated with M\&E in providing Japanese trainees to help with child care and income generation projects in the Hebron office as part of its goal to improve women's' health and quality of life in rural areas. It paid the women's salaries and donated two vehicles to M\&E. M\&E employees helped train the Japanese women. While the collaboration was drawing to a close at the end of the period of study, Peace on Earth continued to draw on M\&E's expertise concerning women in rural areas as it embarked on a new collaboration with a NGO involved in hydrology, based on the same principles of training local Palestinians and then withdrawing. As part of the collaboration, Peace on Earth also made representations on behalf of M\&E to the Japanese Embassy, which resulted in $\$ 93,000$ for a new building in Gaza.

completed shortly after the period of study

The United National Children's Fund is dedicated to providing children with better health and nutrition. It collaborated with M\&E in a joint training program whereby M\&E's employees developed the expertise to train breast-feeding counselors. M\&E thus became qualified to carry out all the training of hospital personnel responsible for teaching mothers to breast-feed their infants, following which UNICEF would register the hospitals as "baby-friendly." This "training of trainers" was a new activity for teaching mothers to breast-feed their infants, following which UNICEF would register the hospitals as "baby-friendly.” This "training of trainers" was a new act
for M\&E. UNICEF contributed \$1,500, equipment and personnel to the joint training program, and the British Consulate and the Australian Embassy contributed funding to implement training programs in two hospitals, thus commencing a new accreditation system of hospitals in the region. As a result of the collaboration UNICEF learned about nutrition in the region and appointed a field officer to the region following the collaboration.

F, Australian

British Consulate:

commenced and completed

during period of study

World Food

Program:

commenced and completed

during period of study

The World Food Program is the food aid organization of the United Nations. It collaborated with M\&E to distribute food to M\&E's 100 neediest families in a way that ensured food security (preventing food being sold on the black market) and combined the provision of food with nutritional education (e.g., women were taught how to cook and use the food). M\&E employees selected the families and distributed the food. Both partners participated in the evaluation to discern methods of targeting families, ensuring secure food distribution, and to combine food distribution with nutritional education. WFP used these new methods in subsequent collaborations with other regional NGOs.

Oxfam:

Oxfam is an organization dedicated to the relief of suffering in terms of both emergency relief and community development. Oxfam and M\&E collaborated on

commenced and completed

during period of study

Pharmaciens sans

Frontièrs: commenced 
during period of study and

ongoing 
TABLE 2: SUMMARY OF DATA ANALYSIS

\begin{tabular}{|c|c|c|c|c|}
\hline & Médecins Sans Frontièrs & Care International & Oslo School of Nutrition & Peace on Earth \\
\hline \multicolumn{5}{|c|}{ Collaboration Characteristics } \\
\hline $\begin{array}{l}\text { Interaction } \\
\text { among } \\
\text { organizations }\end{array}$ & $\begin{array}{l}\text { Deep, } \text { Narrow } \\
\text { - } \quad \text { M\&E manager-MSF manager } \\
\bullet \quad \text { Psychologists-M\&E employees } \\
\bullet \quad \text { Psychologists-MSF hierarchy }\end{array}$ & $\begin{array}{l}\text { Deep, Broad } \\
\text { - } \quad \text { M\&E manager-CI manager } \\
\text { - } \quad \text { CI employees-M\&E employees } \\
\text { - } \quad \text { CI manager-Australian Embassy }\end{array}$ & $\begin{array}{ll}\text { Deep. } \text { Broad } \\
\text { - } \quad \text { M\&E manager-Oslo academics } \\
\text { - } \quad \text { Oslo academics-M\&E employees } \\
\text { - } \quad \text { Oslo academics-M\&E-ministries } \\
\text { - } \quad \text { Oslo academics-M\&E- NGOs } \\
\end{array}$ & $\begin{array}{ll}\text { Deep, } \text { Broad } \\
\text { - } \quad \text { M\&E manager-PoE manager Japanese } \\
\quad \text { trainees-M\&E employees } \\
\text { - } \quad \text { Japanese visitors-M\&E employees } \\
\text { - } \quad \text { PoE manager-Japanese Embassy } \\
\end{array}$ \\
\hline $\begin{array}{l}\text { Coalitional } \\
\text { structure }\end{array}$ & $\begin{array}{l}\text { Partnership } \\
\text { - } \quad \text { M\&E \& MSF work as partners } \\
\text { delivering psychological counseling as } \\
\text { part of nutritional support }\end{array}$ & $\begin{array}{l}\text { Partnership } \\
\text { - Care and M\&E act as partner on micro } \\
\text { loan scheme } \\
\text { Representation } \\
\text { - Care represents M\&E to Australian } \\
\quad \text { Embassy } \\
\end{array}$ & $\begin{array}{l}\text { Partnership } \\
\text { - } \quad \text { M\&E and Oslo work as partners on } \\
\text { design of nutritional policy } \\
\text { Representation } \\
\text { - } \quad \text { M\&E and Oslo academics represent } \\
\quad \text { each other to the Ministry } \\
\end{array}$ & $\begin{array}{l}\text { Transaction } \\
\text { - PoE provides funds, personnel, vehicles } \\
\text { Partnership } \\
\text { • Training Japanese women } \\
\text { Representation } \\
\text { - PoE represents M\&E to Embassy } \\
\end{array}$ \\
\hline $\begin{array}{l}\text { Flows of } \\
\text { information }\end{array}$ & $\begin{array}{l}\text { Bi-directional } \\
\text { - } \quad \text { M\&E and MSF learn how } \\
\text { psychological counseling can support } \\
\text { other interventions } \\
\text { - } \quad \text { MSF learns that psychological } \\
\text { counseling has stigma and dedicated } \\
\text { clinics are not effective } \\
\text { - MSF learns that access to women in } \\
\text { rural areas is problematic } \\
\end{array}$ & $\begin{array}{l}\text { Bi-directional } \\
\text { - } \quad \text { CI learns that access to women in rural } \\
\text { communities difficult } \\
\text { - CI and M\&E learn that existing micro- } \\
\text { credit schemes exclude poorer women } \\
\text { CI and M\&E learn how income } \\
\text { generation schemes can be set up } \\
\text { Multi-directional } \\
\text { - Australian Embassy learns from M\&E }\end{array}$ & $\begin{array}{ll}\text { Bi-directional } \\
\text { - } & \text { M\&E learns of a new potential } \\
\text { - } & \text { Ompetitor } \\
& \text { nutritional expertise } \\
\text { - } & \text { Oslo learns to use M\&E's expertise in } \\
\text { working with ministry } \\
\text { Multi-directional } \\
\text { - } \quad \text { Ministry and NGOs learn about M\&E } \\
\end{array}$ & $\begin{array}{l}\text { Bi-directional } \\
\text { - } \quad \text { PoE develops expertise as a result of } \\
\text { training by M\&E } \\
\text { - M\&E learns about Japanese Embassy } \\
\text { wanting to fund NGOs in the region } \\
\text { Multi-directional } \\
-\quad \text { Japanese Embassy learns about M\&E }\end{array}$ \\
\hline Involvement & $\begin{array}{ll}\text { High } \\
\bullet \quad \text { Deep interaction } \\
-\quad \text { Partnership } \\
\text { - } \quad \text { Bi-directional flows }\end{array}$ & $\begin{array}{ll}\text { High } \\
\bullet \quad \text { Deep interaction } \\
-\quad \text { Partnership } \\
\text { - } \quad \text { Bi-directional flows }\end{array}$ & \begin{tabular}{ll}
\multicolumn{2}{l}{ High } \\
$-\quad$ Deep interaction \\
- $\quad$ Partnership \\
- $\quad$ Bi-directional flows
\end{tabular} & $\begin{array}{ll}\text { High } \\
\bullet \quad \text { Deep interaction } \\
\bullet \quad \text { Partnership } \\
\text { - } \quad \text { Bi-directional flows }\end{array}$ \\
\hline Embeddedness & $\begin{array}{ll}\text { Low } & \\
-\quad & \text { No broad interaction } \\
- & \text { No representation } \\
- & \text { No multi-directional flows } \\
\end{array}$ & \begin{tabular}{ll}
\multicolumn{2}{l}{ High } \\
- $\quad$ Broad interaction \\
$-\quad$ Representation \\
- $\quad$ Multi-directional flows \\
\end{tabular} & $\begin{array}{ll}\text { High } \\
\text { - } \quad \text { Broad interaction } \\
\text { - } \quad \text { Representation } \\
\text { - } & \text { Multi-directional flows } \\
\end{array}$ & \begin{tabular}{ll}
\multicolumn{2}{l}{ High } \\
- $\quad$ Broad interaction \\
- $\quad$ Representation \\
- & Multi-directional flows \\
\end{tabular} \\
\hline \multicolumn{5}{|l|}{ Effects } \\
\hline Strategic & $\begin{array}{l}\text { High: } \text { distinctive } \\
\text { - } \quad \text { Two psychologists in Hebron office } \\
\text { - } \quad \text { Training of M\&E employees } \\
\end{array}$ & $\begin{array}{l}\text { High: distinctive } \\
\text { - Training of M\&E employees in income } \\
\text { generation projects }\end{array}$ & $\begin{array}{l}\text { High: distinctive } \\
\text { - Training of M\&E employees in policy } \\
\text { development }\end{array}$ & $\begin{array}{l}\text { High: } \text { distinctive } \\
\text { - Training of Japanese trainees }\end{array}$ \\
\hline $\begin{array}{l}\text { Knowledge } \\
\text { creation }\end{array}$ & $\begin{array}{l}\text { Medium } \\
\text { - New practices to apply MSF's expertise } \\
\text { in mental health to a substantive area, } \\
\text { developed in the collaboration with } \\
\text { M\&E, are diffused by MSF through a } \\
\text { subsequent collaboration with another } \\
\text { agency working with children who have } \\
\text { been in jail }\end{array}$ & $\begin{array}{l}\text { Medium } \\
\text { - New practices concerning targeting and } \\
\text { accessing small groups of impoverished } \\
\text { women in rural communities, developed } \\
\text { in the collaboration with M\&E, are } \\
\text { diffused by Care through a subsequent } \\
\text { collaboration with a local NGO } \\
\text { working with Palestinian women } \\
\end{array}$ & $\begin{array}{l}\text { High } \\
\text { - New practices concerning nutritional } \\
\text { policy are diffused through a number of } \\
\text { organizations as the Ministry of Health } \\
\text { approves M\&E’s nutritional strategy } \\
\text { and approves an administrative } \\
\text { structure for nutrition within the } \\
\text { Ministry of Health } \\
\end{array}$ & $\begin{array}{l}\text { Medium } \\
\text { - New practices concerning the training } \\
\text { of local Palestinians, developed in the } \\
\text { collaboration with M\&E, are diffused } \\
\text { by PoE through a subsequent } \\
\text { collaboration with a local hydrology } \\
\text { NGO }\end{array}$ \\
\hline Political & Low & $\begin{array}{l}\text { High } \\
\text { - M\&E secures ongoing access to the } \\
\quad \text { Australian Embassy }\end{array}$ & $\begin{array}{l}\text { High } \\
\text { - M\&E secures ongoing access to } \\
\text { Ministry of Health, other ministries, } \\
\text { other NGOs, Norwegian NGOs, } \\
\end{array}$ & $\begin{array}{l}\text { Medium } \\
-\quad \text { M\&E secures ongoing access to the } \\
\quad \text { Japanese Embassy }\end{array}$ \\
\hline
\end{tabular}


\begin{tabular}{|l|l|l|}
\hline & Norwegian Embassy, other embassies \\
\hline
\end{tabular} 
TABLE 2 (CONTINUED): SUMMARY OF DATA ANALYSIS

\begin{tabular}{|c|c|c|c|c|}
\hline & UNICEF & World Food Program & Pharmaciens sans Frontiers & Oxfam \\
\hline \multicolumn{5}{|c|}{ Collaboration Characteristics } \\
\hline $\begin{array}{l}\text { Interaction } \\
\text { among } \\
\text { organizations }\end{array}$ & $\begin{array}{ll}\text { Deep, } \text { Broad } \\
\text { - } & \text { M\&E manager-UNICEF manager } \\
\text { - } & \text { UNICEF employees-M\&E employees } \\
\text { - } & \text { M\&E employees-other breast-feeding } \\
& \text { trainers/counselors } \\
\text { - } \quad \text { M\&E manager - Australian Embassy } \\
\quad \text { and British Consulate }\end{array}$ & $\begin{array}{l}\text { Deep, } \text { Narrow } \\
\text { - M\&E manager-WFP manager } \\
\text { - } \quad \text { M\&E and WFP employees work } \\
\quad \text { together on joint evaluation }\end{array}$ & $\begin{array}{l}\text { Shallow, Narrow } \\
-\quad \text { M\&E manager-PSF manager }\end{array}$ & $\begin{array}{l}\text { Shallow and Narrow } \\
-\quad \text { M\&E manager-Oxfam manager }\end{array}$ \\
\hline $\begin{array}{l}\text { Coalitional } \\
\text { structure }\end{array}$ & \begin{tabular}{ll}
\multicolumn{2}{l}{ Transaction } \\
- & UNICEF provides funds for equipment \\
& and personnel \\
- & Australian Embassy and British \\
& Consulate provide funds \\
Partnership \\
- $\quad$ Joint training of trainers \\
- $\quad$ Joint registration of hospitals \\
\end{tabular} & $\begin{array}{l}\text { Transaction } \\
\text { - } \quad \text { M\&E receives food from WFP to } \\
\quad \text { distributes to neediest families } \\
\text { Partnership } \\
\text { - } \quad \text { M\&E helps WFP to select families and } \\
\text { distribute food } \\
\text { - Joint evaluation of distribution of food }\end{array}$ & \begin{tabular}{|l} 
Transaction \\
$\bullet \quad$ PSF provides medicines
\end{tabular} & $\begin{array}{l}\text { Transaction } \\
-\quad \text { Oxfam provides funds to M\&E to carry } \\
\text { out nutritional survey }\end{array}$ \\
\hline $\begin{array}{l}\text { Flows of } \\
\text { information }\end{array}$ & $\begin{array}{l}\text { Bi-directional } \\
\text { UNICEF learns about M\&E, nutrition } \\
\text { and the region } \\
\text { M\&E learns how to train trainers } \\
\text { Multi-directional } \\
\text { - Hospitals learn how to get UNICEF } \\
\quad \text { accreditation } \\
\end{array}$ & $\begin{array}{l}\text { Bi-directional } \\
\text { - } \quad \text { WFP learns that food can be used to } \\
\text { support M\&E's activities } \\
\text { - WFP learns how to target food } \\
\text { - } \quad \text { M\&E learns how to improve security of } \\
\text { food distribution }\end{array}$ & $\begin{array}{l}\text { Unidirectional } \\
-\quad \text { PSF learns that M\&E uses medicines }\end{array}$ & $\begin{array}{l}\text { Unidirectional } \\
-\quad \text { Oxfam learns about M\&E’s expertise }\end{array}$ \\
\hline Involvement & \begin{tabular}{ll}
\multicolumn{2}{l}{ High } \\
- $\quad$ Deep interaction \\
- $\quad$ Partnership \\
- $\quad$ Bi-directional flows
\end{tabular} & \begin{tabular}{ll}
\multicolumn{2}{l}{ High } \\
- $\quad$ Deep interaction \\
$-\quad$ Partnership \\
- $\quad$ Bi-directional flows
\end{tabular} & \begin{tabular}{|ll} 
Low & \\
& No deep interaction \\
- & No partnership \\
& No bi-directional flows \\
\end{tabular} & $\begin{array}{ll}\text { Low } & \\
\text { - } & \text { No deep interaction } \\
\text { - } & \text { No partnership } \\
\text { - } & \text { No bi-directional flows } \\
\end{array}$ \\
\hline Embeddedness & $\begin{array}{ll}\text { Medium } \\
\bullet \quad \text { Broad interaction } \\
-\quad \text { No representation } \\
-\quad \text { Multi-directional flows } \\
\end{array}$ & $\begin{array}{ll}\text { Low } & \\
-\quad & \text { No broad interaction } \\
- & \text { No representation } \\
-\quad & \text { No multi-directional flows } \\
\end{array}$ & 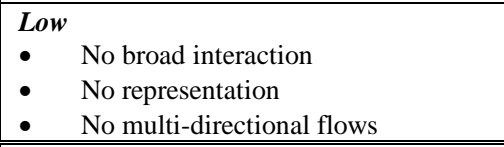 & $\begin{array}{ll}\text { Low } & \\
- & \text { No broad interaction } \\
- & \text { No representation } \\
-\quad & \text { No multi-directional flows } \\
\end{array}$ \\
\hline \multicolumn{5}{|l|}{ Effects } \\
\hline Strategic & $\begin{array}{l}\text { High: distinctive } \\
\text { - Training of M\&E employees in breast- } \\
\quad \text { feeding counseling } \\
\end{array}$ & $\begin{array}{l}\text { High: distinctive } \\
\text { - Training of WFP in targetting food } \\
\text { distribution } \\
\end{array}$ & Low: not distinctive & Low: not distinctive \\
\hline $\begin{array}{l}\text { Knowledge } \\
\text { creation }\end{array}$ & $\begin{array}{l}\text { Medium } \\
\text { - New practices concerning “baby- } \\
\text { friendly" accreditation, developed as a } \\
\text { result of the collaboration with M\&E } \\
\text { are diffused by M\&E to hospitals in the } \\
\text { region }\end{array}$ & $\begin{array}{l}\text { Medium } \\
\text { - New practices concerning food } \\
\text { distribution programs, developed as a } \\
\text { result of the collaboration with M\&E, } \\
\text { are diffused by WFP through other } \\
\text { collaborations with NGOs in the region }\end{array}$ & Low: no new practices & Low: no new practices \\
\hline Political & $\begin{array}{l}\text { High } \\
\text { - M\&E secures ongoing access to two } \\
\text { hospitals, Australian Embassy and } \\
\end{array}$ & Low & Low & Low \\
\hline
\end{tabular}




\section{NOTES}

${ }^{1}$ This study is an extension of previous Lawrence, Hardy and Phillips (forthcoming) that explores the institutional effects of collaboration.

${ }^{2}$ Mère et Enfant is a pseudonym; collaborating organizations are referred to by their real names.

${ }^{3}$ We excluded only one case where an attempt to collaborate was never realized, on the grounds that it did not constitute a collaboration. We are not interested in what makes collaboration successful in this paper, but in the effects of successful collaborations. 


\section{University Library}

\section{- M M I N E R VA A gateway to Melbourne's research publications}

Minerva Access is the Institutional Repository of The University of Melbourne

Author/s:

Hardy, C;Phillips, N;Lawrence, TB

Title:

Resources, knowledge and influence: The organizational effects of interorganizational collaboration

Date:

2003-03-01

\section{Citation:}

Hardy, C., Phillips, N. \& Lawrence, T. B. (2003). Resources, knowledge and influence: The organizational effects of interorganizational collaboration. JOURNAL OF MANAGEMENT STUDIES, 40 (2), pp.321-347. https://doi.org/10.1111/1467-6486.00342.

Persistent Link:

http://hdl.handle.net/11343/116079 